\title{
COMPARISON OF THE PASS SKILL BETWEEN PROFESSIONAL AND U-15 FUTSAL PLAYERS UNDER DIFFERENT ORGANIZATION CONTEXTS
}

original paper

(1) University School of Physical Education in Wroclaw

DOI: https://doi.org/10.5114/hm.2020.89915

\section{NERYLSON FERRAZ PAZETTO, JOSÉ GUILHERME MAFRA GAINO, CLEBERSON DUTRA DOS SANTOS, RODRIGO MARTINS DE OLIVEIRA SPINOSA, DALBERTO LUIZ DE SANTO, INARA MARQUES}

Londrina State University, Londrina, Brazil

\begin{abstract}
Purpose. The paper aimed to compare the performance related to passing among the categories of professional and U-15 futsal players, in open and closed contexts.

Methods. In total, 25 athletes were evaluated in 2 tests, namely open and closed contexts. The former aimed to observe the complexity of in-game execution in a dynamic and unpredictable mode, while the closed test simulated a closed and predictable task through the isolated execution of the pass. To compare the groups, the Student's $t$ and Mann-Whitney tests were used, respectively, with the level of significance at $p<0.05$.

Results. There were significant differences across categories in the performance related to the open pass skill $(p<0.001)$. There were no significant differences in the closed pass context $(p=0.414)$.

Conclusions. Only the open context test identified differences in performance between categories, with the superiority of professional players.
\end{abstract}

Key words: motor skills, technical performance, passing, tests, futsal

\section{Introduction}

As futsal has a smaller number of players and playing space compared with soccer, players are required to participate more frequently in the rapid events of the game, through decision making and the execution of motor skills. Therefore, rapid decision making and pass accuracy are considered important requirements for futsal players [1].

According to a systematic review study [2], the performance of motor skills is evaluated for various purposes, for example, to verify the frequency of success in the performance of the skills (a) through the effect of fatigue stimulated by physical exercises or (b) in conditioned game situations through different task restrictions, such as modified rules, fewer players, less space, or limited contact with the ball; (c) to compare athletes of different categories, competitive levels, playing positions, and tactical schemes; and (d) to identify and select potentially talented players. Thus, there are different ways of evaluating the performance of the same specific motor skills, the main factor being the characteristics of the environment where they occur.

Evaluating the performance of motor skills in collective sports is usually based on observations of closed tasks, isolated from the game, such as dribbling between cones, kicking, and passing to a fixed target [3]. It is understood that in closed tasks the skill is executed in an unchanging, predictable environment, i.e., in this context, the player can evaluate the environment in advance, organize their movements, and perform the action without any need for sudden adjustments [4].

On the other hand, in open tasks, players are required to adapt their actions to the emerging situations, owing to the unpredictability of the events and complexity of the space-time restrictions of the envi-

Correspondence address: Nerylson Ferraz Pazetto, Centro de Educação Física e Esporte, Rodovia Celso Garcia Cid, PR-445, Km 380, Campus Universitário, Londrina - PR, Brazil, e-mail: itonerylson@hotmail.com

Received: May 14, 2019

Accepted for publication: August 23, 2019

Citation: Pazetto NF, Gaino JGM, Dos Santos CD, De Oliveira Spinosa RM, De Santo DL, Marques I. Comparison of the pass skill between professional and U-15 futsal players under different organization contexts. Hum Mov. 2020;21(2):58-63; doi: https://doi.org/10.5114/hm.2020.89915. 
ronment, such as their position on the court, the position and speed of movement of teammates and opponents, and distances between players and between each pass possibility [5]. Because of this, players with excellent performance in closed motor skills may not be able to execute them effectively in matches if they do not know when and where to apply them [6].

Therefore, evaluating motor skills of players in closed tasks is questionable, and the need is highlighted to observe them in open context situations, with greater ecological validity $[3,7,8]$. Thus, studies have used observational methodology, based on the analysis of match footage, which enables recording and quantification of the performance of players and teams in tactical-technical behaviours at various moments of the game [9-11], as well as in the application of open context tests, aiming to better simulate the execution of skills in game $[1,12]$.

However, it is understood that there is a gap in the literature regarding the comparison of the motor skills performance of futsal players of different categories in open and closed context tests in order to investigate whether an open context evaluation would allow more efficient discrimination of the skill and level of athletes. Thus, the present study aimed to compare the performance of professional and U-15 futsal players in the pass skill in open and closed context tests. It was hypothesized that professional players would only perform significantly better than elite U-15 athletes in open pass ability.

\section{Material and methods}

\section{Participants}

The study included a sample of 25 male futsal athletes from 2 categories: the professional category $(n=10$, with a mean age of $20.76 \pm 4.82$ years and average practice time of $13.3 \pm 4.76$ years, participating in the third division of the futsal championship of Paraná) and the U-15 category $(n=15$, with a mean age of $14.59 \pm 0.62$ years and average practice time of 8.66 \pm 1.49 years, participating in the first division of the metropolitan futsal league of Londrina). Data collection was performed at the beginning of the team competition period, and both teams used the tactical periodization training methodology. All subjects received detailed information on the study procedures, aims, and risks.

\section{Description of the tasks and procedures}

Two tests were applied to evaluate player performance in ball passing, observed under 2 context conditions, denominated open context (Figure 1) and closed context (Figure 2). The participants were able to choose the lower limb and form that they judged most appropriate for the execution of the passes in the tests. Regarding the order of test performance, the evaluator assigned half of the participants to start with each test.

\section{Open context test}

The open context test in the present study was developed to evaluate the performance of futsal players in the pass skill and intended to simulate the complexity of the pass skill execution in a match situation, specifically, maintaining team possession of the ball. The test featured a dynamic aspect, through the joining of various skills (pass, dominance, and conduction), with unpredictability in the environment (where to execute the pass?) and time pressure, requiring the ball carrier to quickly perceive which

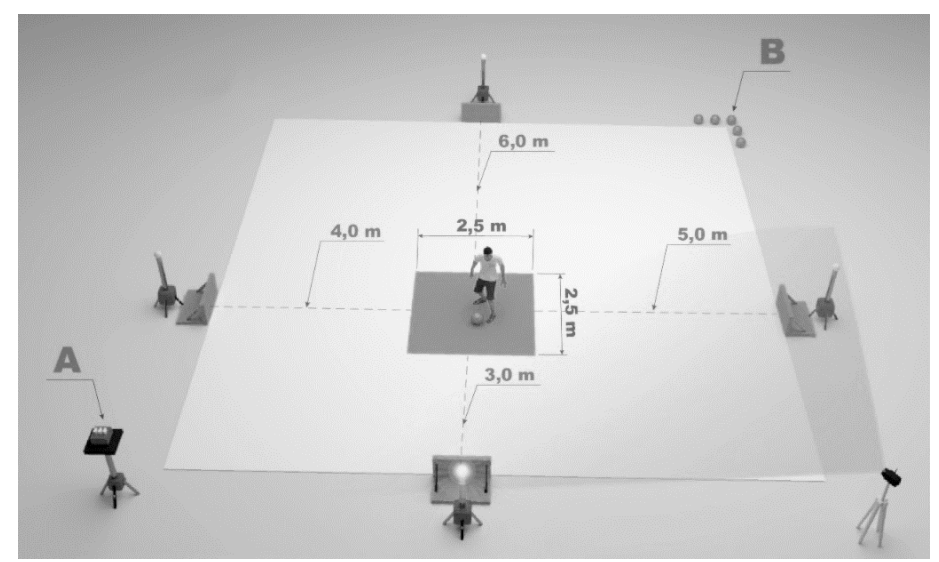

Figure 1. Open context test to evaluate performance in the pass skill

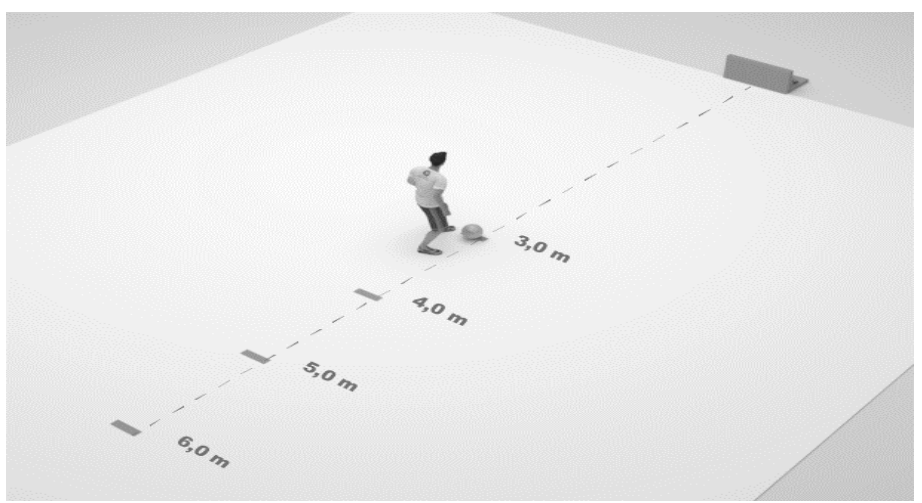

Figure 2. Closed context test to evaluate performance in the pass skill 
'teammates' (targets) would be in a better condition to receive the pass quickly and accurately. The test was composed of 4 targets $(1 \mathrm{~m}$ wide $\times 0.40 \mathrm{~cm}$ high), a light tower $60 \mathrm{~cm}$ high behind each target, which illuminated, unpredictably, one of the 4 options to the participant, lighting equipment, tape to mark the pass area, 6 balls, and a camera.

Evaluator A was positioned at one of the vertices of the test area with the equipment that controlled the light towers (station A). Evaluator B was positioned in the opposite vertex, to give another ball to the participants when the ball went outside the test area (station $\mathrm{B}$ ). In the vertex to the right of station $\mathrm{A}$, evaluator $\mathrm{C}$ was positioned with a Sony XYZ camera (station $\mathrm{C}$ ).

The distances to execute the passes to the targets were pre-defined as 3, 4, 5, and 6 meters, firstly, because of the variability in distances when performing passes in matches, as when in possession of the ball, teammates are positioned at different distances, and secondly, because distances greater than 6 meters could prevent the return of the ball for the participant to dominate it, which would detract from the dynamic aspect of the test.

At the beginning of the test, the participant was positioned in the centre of the pass area, marked with tape on the floor of the court $(2.5 \times 2.5 \mathrm{~m})$, with the ball between their feet and facing the target at a distance of $3 \mathrm{~m}$. Evaluator A explained the rules of the test: (a) execute 12 successful passes as fast as possible to the target whose light is on; (b) to validate the hit, the ball cannot be completely outside the pass area; (c) if necessary, the player may leave the pass area to retrieve the ball; however, they must return the ball to execute the next pass; (d) the player must not touch the ball with the hands; (e) if the pass goes out of the test area, evaluator B will provide another ball. Next, the evaluator said the word 'ready' to start the test and pressed one of the buttons to light one of the 4 light towers.

The participants were familiarized with the test by performing a successful pass to each target triggered by evaluator $\mathrm{A}$ at increasing distances from the targets (3, 4, 5, 6 meters). If there were no doubts, in order to record the data, the participants performed 2 sets of 12 successful passes to the illuminated targets. A 20-second rest interval was allowed between each series of passes.

Each set was performed in a pre-established sequence (Table 1) so that the test condition was the same for all participants, to eliminate the possibility of benefiting some participants with sequences of passes with smaller distances. It can be observed that both
Table 1. Sequence of previously established distances from passes to targets (meters) for the open context test

\begin{tabular}{ll}
\hline $1^{\text {st }}$ series & $4-3-6-4-5-6-5-3-5-4-6-3$ \\
$2^{\text {nd }}$ series & $5-3-6-5-4-6-4-3-4-5-6-3$ \\
\hline
\end{tabular}

series were formed by 3 successful passes to each target, and at 4 moments the target was fired to the right, left, and back of the participant.

After the command to start the test, the participant needed to quickly establish which lamp was lit to execute a fast and accurate pass to the respective target. At the moment the ball hit the target, evaluator A simultaneously turned off the lamp and lit the next one. Upon return of the ball, the participant was required to efficiently control the ball at the same time as spatially positioning themselves to better identify the next lit target and thus execute the next pass.

Three types of errors were adopted in the execution of the pass: (a) execution of the pass at an unlit target; (b) passing the ball completely out of the pass area, reaching the target; and (c) passing inaccurately out of the test area. In the case of type (a) and (b) errors, the participant could continue the test with the same ball returned from the target. In the case of error type (c), the participant immediately received another ball from evaluator $B$, through a pass towards the pass area.

When any of these errors occurred, evaluator A did not turn off the light of the respective target; in this way, the participant was required to execute further passes until hitting that target, after which the next light was lit. Therefore, passing errors during the test carried a penalty for the participant, by adding time to their performance. The time to complete each series was calculated by watching the footage. For the statistical analyses, the time of the series in which the participant completed the 12 successful passes most quickly was considered.

\section{Closed context test}

The closed context test in the present study was developed to evaluate the performance of futsal players in the pass skill. The test was intended to represent the predictable characteristics of performance tests in the pass skill described in the literature, e.g. by Mor and Christian [13] and the Portuguese Football Federation [14], where the ball was statically placed in certain positions in relation to a specific target, in order to accurately execute the pass.

The distances used for the execution of the passes 
Table 2. Sequence of previously established distances from passes to targets (meters) for the closed context test

\begin{tabular}{ll}
\hline $1^{\text {st }}$ series & $5-3-6-5-4-6-4-3-4-5-6-3$ \\
$2^{\text {nd }}$ series & $4-3-6-4-5-6-5-3-5-4-6-3$ \\
\hline
\end{tabular}

and the size of the target were the same as established in the open context test. Adhesive tape was fixed to the ground of the court at the distances of $3,4,5$, and 6 meters in relation to the centre of the target, on which the motionless ball was positioned.

The participants were familiarized with the test by performing a pass to the target at each distance, in ascending order. Then, 2 series of 12 target passes were performed for data recording, 3 in each position, in accordance with the sequence previously defined and presented in Table 2.

Prior to each attempt to execute the pass, the evaluator informed the participant as to which distance the ball should be statically positioned. The participant was allowed to move up to 2 meters behind the ball to aim at it and execute the pass to the target. After each pass attempt, the evaluator recorded 1 point if the outcome was successful (hit the target) or 0 points if unsuccessful. Thus, the performance score in the test could range from 0 to 12 points for each player. For the statistical tests, the score obtained by each participant in their best series of passes was used.

\section{Statistical analysis}

The variables were tested to verify the data distribution with the Shapiro-Wilk normality test. As there was normality of the data in the variable pass performance in the open context, we chose the Student's $t$-test for independent samples for comparisons between the 2 categories. In turn, as there was no normality of the variable pass in the closed context, the MannWhitney test was used for comparison between the
2 categories. The SPSS 23.0 statistical software was utilized and statistical significance of the differences was accepted at $p<0.05$.

\section{Ethical approval}

The research related to human use has complied with all the relevant national regulations and institutional policies, has followed the tenets of the Declaration of Helsinki, and has been approved by the Londrina State University Ethics Committee.

\section{Informed consent}

Informed consent has been obtained from all individuals included in this study.

\section{Results}

Table 3 presents the results of the comparisons between the professional and U-15 categories in pass performance in the open context.

A significant difference was observed in performance between the categories analysed in the pass skill in the open context test ( $p<0.001)$, with mean values of $34 \%$ of superior performance in professional players compared with U-15 players.

Table 4 presents the results of the performance comparison between the professional and U-15 categories in the pass skill in the closed context test. It can be observed that there were no significant differences in performance between the groups in the pass skill in the closed context $(p=0.414)$.

\section{Discussion}

The objective of the study was to compare the performance of futsal players between the professional and U-15 categories in the pass skill in open and closed context tests. The choice of these categories allowed the evaluation of athletes who, in terms of motor de-

Table 3. Comparison of performance (s) between categories in the pass skill in the open context

\begin{tabular}{lcccccccc}
\hline Group & $n$ & Median & Min. & Max. & Mean & $S D$ & $t$ & $p$ \\
\hline U-15 & 15 & 35.63 & 29 & 48.3 & 37.36 & \pm 6.25 & 5.4 & $<0.001$ \\
Professional & 10 & 27.92 & 23.7 & 31 & 27.88 & \pm 2.53 & \\
\hline
\end{tabular}

Table 4. Comparison of performance (points: 0-12) between categories in the pass skill in the closed context

\begin{tabular}{lcccccccc}
\hline Group & $n$ & Median & Min. & Max. & Mean & $S D$ & $U$ & $p$ \\
\hline U-15 & 15 & 12 & 11 & 12 & 11.93 & \pm 0.27 & 70 & 0.414 \\
Professional & 10 & 12 & 12 & 12 & 12 & \pm 0 & \\
\hline
\end{tabular}


velopment, were already mature in the specialized motor phase [15] and therefore differed only in training experience.

In the closed context test, the results showed no differences in performance between the categories in the ability to pass, which can be explained by the low complexity of restrictions on the execution of the pass, facilitating good performance. On the other hand, the increased training experience of professional players may have influenced the significantly higher performance in passing ability in the open context test. Thus, the difference found between the categories only in the open context test can be explained by the increased requirement of the test, as it simulated more closely the complexity of playing skills in a game situation, i.e., presented more ecological testing characteristics.

The result of the closed context test in the present study corroborates 5 other studies that found no significant differences in performance between groups of soccer players in the ability to pass in closed context tests. With the Mor-Christian test [13], the study by Soares et al. [16] compared performance between U-14 and U-15 categories, Machado et al. [17] and Feltrin and Machado [18] investigated young players from different playing positions (centre-half, defender, midfield, striker). Malina et al. [19] applied the test battery proposed by the Portuguese Football Federation [14] in players aged 13-15 years of different positions in the game (defence, mid-field, attack). Joo and Seo [20] also evaluated the performance of school players of different positions (goalkeepers, defence, midfield, and attack).

The result of the open context test in the present study differs from research that did not find significant superiority in the performance of players of more advanced categories in open skills. Examples include the comparison of futsal players of U-7, U-9, and U-11 categories in the percentage of successful offensive technical actions based on observations of game footage [11], as well as the study by Koltai et al. [21] with soccer players of different age categories (U-15, U-17, and professional) evaluated with a test similar to the open context test applied in the present study.

It should be noted that, generally, studies investigate the motor skill performance of players of different competitive levels. Naser and Ali [1] found no significant superiority in the performance of top-level adult futsal players (elite, semi-elite, and social) in pass ability assessed with the Loughborough Soccer Passing Test (LSPT), proposed by Ali et al. [12]. On the other hand, soccer studies that used LSPT dem- onstrated significantly superior performance of elite athletes in comparison with lower competitive levels, with adult participants [12], female players [22], and young players aged $14-17$ years [23]. Although LSPT presents similarity with the open context test in the present research, in this study the information presented to the participant regarding the place to execute the pass was visual and non-verbal, similar to that in a game, which allows greater ecological validity of the evaluation.

Therefore, it is considered that the evaluation of motor skills performance in the open context has greater ecological validity compared with closed skills tests $[3,7,8]$. Because of this, in the passing ability in the different age categories investigated, the present study pointed out that only the open context test presented valid characteristics in discriminating between the performance of more and less experienced athletes. However, the study has the limitation of not having provided information on the agreement of the evaluators in the measures, or the reliability of the tests.

Pragmatically, the results presented in this study could be scientifically useful in guiding researchers in choosing open context tests that simulate game characteristics, as well as guiding coaches in prioritizing training exercises that require the execution of open skills, composing the characteristics of the game, as evidenced in the study by Práxedes et al. [24], where the practice based on reduced games, with modified rules and numerical superiority to attack favoured significant improvement in athletes' performance in decision making and pass execution compared with the practice prioritized in the exercise of closed motor skills.

\section{Conclusions}

It is concluded that only the open context test was able to seize the significant superiority of the performance of professional futsal athletes in the pass skill.

\section{Disclosure statement}

The first author received financial support from the Coordenação de Aperfeiçoamento de Pessoal de Nível Superior (CAPES, Coordination for the Improvement of Higher Education Personnel), Public Notice PEF $24 / 2017$.

\section{Conflicts of interest}

The authors state no conflict of interest. 


\section{References}

1. Naser N, Ali A. A descriptive-comparative study of performance characteristics in futsal players of different levels. J Sports Sci. 2016;34(18):1707-1715; doi: 10. 1080/02640414.2015.1134806.

2. Aquino R, Puggina EF, Alves IS, Garganta J. Skill-related performance in soccer: a systematic review. Hum Mov. 2017;18(5):3-24; doi: 10.1515/humo-2017-0042.

3. Aquino R, Marques RFR, Petiot GH, Gonçalves LGC, Moraes C, Santiago PRP, et al. Relationship between procedural tactical knowledge and specific motor skills in young soccer players. Sports. 2016;4(4):E52; doi: $10.3390 /$ sports 4040052 .

4. Schmidt RA, Lee TD. Motor learning and performance: from principles to application, $5^{\text {th }}$ ed. Champaign: $\mathrm{Hu}-$ man Kinetics; 2014.

5. Graça A. The hows and whens of game teaching [in Portuguese]. In: Graça A, Oliveira J (eds.), Teaching sports games [in Portuguese]. Porto: Centro de Estudos dos Jogos Desportivos; 1998; 27-34.

6. Turner A, Martinek TJ. Teaching for understanding: a model for improving decision making during game play.Quest.1995;47(1):44-63; doi:10.1080/00336297. 1995.10484144.

7. Ali A. Measuring soccer skill performance: a review. Scand J Med Sci Sports. 2011;21(2):170-183; doi: 10.1111/j.1600-0838.2010.01256.x.

8. Praça GM, Soares VV, Matias CJAS, da Costa IT, Greco PJ. Relationship between tactical and technical performance in youth soccer players. Rev Bras Cineantropom Desempenho Hum. 2015;17(2):136-144; doi: 10.5007/1980-0037.2015v17n2p136.

9. Ferreira A, Santos R, Louro H, Sousa PM, Pinheiro V, Santos F. Notational, sequential, and t-patterns analysis of the tactical schemes of a professional futsal team. Hum Mov. 2018;19(5):29-39; doi: 10.5114/hm.2018. 79737.

10. Pic M. Performance and home advantage in handball. JHum Kinet. 2018;63:61-71; doi: 10.2478/hukin-20180007.

11. Reis M, Santos J, Matos M, Cruz T, Vasconcellos F, Almeida M. Assessment of the performance of novice futsal players in the execution of futsal-specific motor skills. Hum Mov. 2019;20(3):29-37; doi: 10.5114/hm. 2019.83994.

12. Ali A, Williams C, Hulse M, Studwick A, Reddin J, Howarth L, et al. Reliability and validity of two tests of soccer skill. J Sports Sci. 2007;25(13):1461-1470; doi: 10.1080/02640410601150470.

13. Mor D, Christian V. The development of a skill test battery to measure general soccer ability. NCJ Health Phys Ed. 1979;15(1):30-39.

14. Federação Portuguesa de Futebol. Football skills and abilities: "Football skills" [in Portuguese]. Lisboa: Federação Portuguesa de Futebol; 1986.
15. Gallahue D. Classifying movement skills: a case for multidimensional models [in Portuguese]. Rev Educ Fis UEM. 2002;13(2):105-111.

16. Soares VOV, Rodrigues VAO, Praça GM, Matias CJAS, Greco PJ. Technical performance of U-14 and U-15 football players [in Portuguese]. Corpus Sci. 2015;11(1):47-54.

17. Machado JCBP, Netto JMA, Domingues WJR, Bezerra ES. Selection process in soccer under 17: interrelation of physical and technical aspects [in Portuguese]. Rev Educ Fis UEM. 2011;22(1):47-55; doi: 10.4025/ reveducfis.v22i1.9435.

18. Feltrin YR, Machado DRL. Technical ability and physical fitness of youth soccer players [in Portuguese]. Rev Bras Futebol. 2009;02(1):45-59.

19. Malina RM, Cumming SP, Kontos AP, Eisenmann JC, Ribeiro B, Aroso J. Maturity-associated variation in sport-specific skills of youth soccer players aged 13-15 years. J Sports Sci. 2005;23(5):515-522; doi: 10.1080/ 02640410410001729928.

20. Joo CH, Seo DI. Analysis of physical fitness and technical skills of youth soccer players according to playing position. J Exerc Rehabil. 2016;12(6):548-552; doi: 10.12965/jer.1632730.365.

21. Koltai M, Wallner D, Gusztafik Á, Sáfár Z, Dancs H, Simi H, et al. Measuring of sport specific skills of football players. J Hum Sport Exerc. 2016;11(1):S218-S227; doi: 10.14198/jhse.2016.11.Proc1.12.

22. Ali A, Foskett A, Gant N. Validation of a soccer skill test for use with females. Int J Sports Med. 2008;29(11): 917-921; doi: 10.1055/s-2008-1038622.

23. Le Moal E, Rué O, Ajmol A, Abderrahman AB, Hammami MA, Ounis OB, et al. Validation of the Loughborough Soccer Passing Test in young soccer players. J Strength Cond Res. 2014;28(5):1418-1426; doi: 10.1519/ JSC.0000000000000296.

24. Práxedes A, Del Vilar F, Pizarro D, Moreno A. The impact of nonlinear pedagogy on decision-making and execution in youth soccer players according to game actions. J Hum Kinet. 2018;62(1):185-198; doi: 10.1515/ hukin-2017-0169. 